\title{
Controlled Clinical Trials Evaluating the Homeopathic Treatment of People with Human Immunodeficiency Virus or Acquired Immune Deficiency Syndrome
}

\author{
DANA ULLMAN, M.P.H.
}

\begin{abstract}
Context: Homeopathic medicine developed significant popularity in the nineteenth century in the United States and Europe as a result of its successes treating the infectious disease epidemics during that era. Homeopathic medicine is a medical system that is specifically oriented to using nanopharmacologic and ultramolecular doses of medicines to strengthen a person's immune and defense system rather than directly attacking the microbial agents.

Objectives: To review the literature referenced in MEDLINE ${ }^{\mathrm{TM}}$ and in nonindexed homeopathic journals for placebo-controlled clinical trials using homeopathic medicines to treat people with AIDS or who are human immunodeficiency virus (HIV)-positive and to consider a different theoretical and methodological approach to treating people with the viral infection.

Findings: A total of five controlled clinical trials were identified. A double-blinded, placebocontrolled study was conducted on 50 asymptomatic HIV-positive subjects (stage II) and 50 subjects with persistent generalized lymphadenopathy (stage III) in whom individualized singleremedy homeopathic treatment was provided. A separate body of preliminary research was conducted using homeopathic doses of growth factors. Two randomized double-blinded, placebo-controlled studies were conducted with a total of 77 people with AIDS who used only natural therapies over a 8-16-week period. Two other studies were conducted over a 2.5-year period with 27 subjects in an open-label format.

Settings: The first study was conducted by the Regional Research Institute for Homoeopathy in Mumbai, India, under the Central Council for Research in Homoeopathy, with the approval of the Ministry of Health and Family Welfare, Government of India. The second body of studies was conducted in clinic settings in California, Oregon, Arizona, Hawaii, New York, and Washington.

Results: The first study found no statistically significant improvement in CD4 T-lymphocytes, but did find statistically significant pretest and post-test results in subjects with stage III AIDS, in CD4 $(p=0.008)$ and in CD8 $(p=0.04)$ counts. The second group of studies found specific physical, immunologic, neurologic, metabolic, and quality-of-life benefits, including improvements in lymphocyte counts and functions and reductions in HIV viral loads.

Conclusions: As a result of the growing number of people with drug-resistant HIV infection taking structured treatment interruptions, homeopathic medicine may play a useful role as an adjunctive and/or alternative therapy.
\end{abstract}

Homeopathic Educational Services, Berkeley, CA.

No grant or financial support was used for this review of research. 


\section{INTRODUCTION}

$\mathbf{T}$ he homeopathic and ecological approach to all infectious disease presents some new and old insights from which we all may benefit. The clinical work in the homeopathic treatment of people with acquired immunodeficiency syndrome (AIDS) and who are human immunodeficiency virus (HIV)-positive suggests that homeopathic medicines may be a useful treatment as a primary or as an adjunctive treatment for people with AIDS, and it is a topic that needs further study.

It should be noted that surveys in the early 1990s found that between $30 \%$ and $50 \%$ of the HIV-positive population uses alternative therapies (Barton et al., 1994; Singh et al., 1996), while later surveys found between $50 \%$ to $100 \%$ utilization (Carwein and Sabo, 1997; Wooton and Sparber, 2001). A recent nonrandom sample of $100 \mathrm{HIV}$-positive patients at the National Institutes of Health s AIDS clinic found that 91\% had used at least one alternative therapy at some time in their life, $84 \%$ used at least one alternative therapy postdiagnosis with an average of just fewer than five, and the frequency of use of alternative therapies prediagnosis was $64 \%$ (Sparber et al., 2000). One study found that $40 \%$ of men using conventional AIDS therapy were also using alternative therapies (Anderson et al. 1993). A more recent study in Australia found that $11 \%$ of people with HIV or AIDS used alternative therapies only, with $45 \%$ using both conventional and alternative therapies (de Visser et al., 2000). This study also found that women were more likely than men to use only alternative therapies as were people who had experienced side-effects from conventional medical treatment. People with an income below the poverty level were less likely to use alternative therapies.

Although there has been little research to assess physicians attitudes toward the homeopathic treatment of people with AIDS, one survey showed that $50 \%$ of Dutch physicians instigated and supported the use of homeopathic and natural therapies in the treatment of people with AIDS (Wolffers and de Moree, 1994). A survey of 1666 HIV-positive American men and women that was conducted by the Bastyr University AIDS Research Center found that approximately $9 \%$ of HIV-infected individuals who used complementary and alternative medicine were treated by a homeopathic practitioner (Standish, 2002).

\section{HISTORICAL EVIDENCE}

Homeopathy has a history of success in the treatment of infectious disease, including many of the most serious and potentially fatal infectious diseases known to humankind. Death rates in homeopathic hospitals from cholera, typhoid, yellow fever, scarlet fever, and pneumonia were commonly one half to as little as one eighth those in conventional medical hospitals (Bradford, 1900; Coulter, 1975; Leary, 1987). The successes of the homeopathic treatments of infectious diseases during the 1800s in the United States and Europe created significant support for this therapy. Skeptics of homeopathy assert that the positive results in the homeopathic treatment of such infectious diseases are primarily the results of the iatrogenic effects of the conventional treatments of the day. However, homeopathic care was not only provided in hospitals but was also available in select prisons and insane asylums that employed physicians who specialized in homeopathy. These prisons and asylums also experienced a considerably better success rate compared to those prisons and asylums under the care of conventional physicians (Bradford, 1900), even though access to conventional medical treatments in these settings was substantially less.

More recently, the use of homeopathic medicines was tested in conjunction with rehydration in the treatment of a cholera epidemic in Peru where it was found to have positive results (Gaucher et al., 1993).

\section{THE NEED FOR ALTERNATIVES}

Highly active antiretroviral treatment (HAART) is presently the treatment of choice for people with AIDS or who are HIV-positive. These drug cocktails of protease inhibitors and nucleosides led to the first real medical progress in the treatment of this disease. 
Although most conventional physicians and people with AIDS are encouraged by the results of using the cocktail of antiretroviral AIDS medications, a recent study published in the Journal of the American Medical Association found that $27 \%$ of people who are HIV-positive have an infection that is resistant to all three classes of HIV drugs presently available (Voelker, 2000). According to a study conducted by the Rand Institute and the University of California at San Diego, the widespread misuse of anti-HIV drugs has led to drug-resistant infection in at least half of the population undergoing treatment today for this disease and $64 \%$ of patients with HIV are receiving less benefit from their drugs than they were 2 or 3 years ago (Garrett, 2001; Richman et al., 2001).

As for the future, the history of antimicrobial treatment teaches us that drug resistance will predictably increase (Blower, 2001).

All of this evidence suggests that there is a need for alternative medications and therapy for a significant number of people with HIV infection. Even for those people for whom various AIDS drugs are effective, there are substantial numbers of physicians and patients who are recommending structured treatment interruptions (also called "drug vacations") for several weeks, months, or years, in order to reduce of possibility of drug resistance. It may make sense for people with AIDS to consider alternative treatments, such as homeopathic medicines, during these treatment interruptions.

It should be noted, however, that there is no evidence concerning the effects of repeated administration of homeopathic medicines on resistance such as is documented for current antiviral AIDS treatments.

\section{A DIFFERENT APPROACH TO TREATING INFECTIOUS DISEASE}

As horrific as the AIDS epidemic is, it has perhaps one silver lining: it has led to a significant increase in research and knowledge about the immune system.

The medical community has focused a tremendous amount of its AIDS resources on creating antiviral medications to the near ex- clusion of alternative methods. For many years, drug companies and the AIDS community asserted that azidothymidine (AZT) was the great AIDS hope but today, it is generally recognized that AZT taken alone has done more harm than good. More recently there has been a similar fervor for the HAART drug combinations, and once again, research monies for alternative treatments have been minimal.

What is yet to be adequately appreciated in the treatment of people with AIDS is the need to direct more attention and research to ways to augment the immune response, rather than ways to inhibit viral replication. By strengthening a person's own defenses, the body may be best able to defend itself.

Homeopathy may be one way to do this. Whether used along with a conventional drug treatment program, used during a structured treatment interruption, or as an alternative treatment, homeopathic medicine may have a role to play in AIDS care (Ullman, 1995).

Louis Pasteur, who initially suggested that bacteria cause disease, later realized that bacteria may not necessarily be the "cause" of disease as much as the "results" of disease (Dubos, 1959). Similar to Claude Bernard (1947), the father of experimental physiology, Pasteur came to realize that the susceptibility of the individual, the "host resistance," was a greater determinant of the development of disease than the infective agent itself.

Despite the later recanting by Pasteur, he had already set in motion a medical mind set that focused primarily on eliminating pathogens and that ignored exploring ways to augment immune and defense responses. Looking to the future it is not difficult to imagine a similar fate for antiviral and protease inhibiting drugs.

As distinct from conventional drug therapies that primarily work by attacking microbial agents or interfere with their biochemical processes, it is postulated that homeopathic medicine may strengthen a person's immune and defense system to help the person fight the infection. Homeopathy is not just using different medicines and doses of medicines: it is an entirely different approach to infectious disease. 


\section{HIV/AIDS CLINICAL TRIALS TESTING HOMEOPATHIC MEDICINES}

A randomized, double-blinded clinical trial (Rastogi et al., 1999) was conducted with 50 patients with stage II (asymptomatic HIV-positive) and 50 patients with stage III (persistent generalized lymphadenopathy [PGL]). A single, individually chosen homeopathic medicine was prescribed in each case and followed up at intervals of 15 to 30 days for a total of 6 months. Because fluctuations in total lymphocyte counts occur in diurnal cycles, all samples were collected between 9:00 AM and 11:00 AM, and all samples were processed on the same day of collection.

Patients in stage III who were given a homeopathic medicine experienced a statistically significant change in CD4 T-lymphocytes counts $(p=0.008)$. There was also a statistically significant elevation of CD8 T-lymphocytes $(p=$ 0.04). Patients in stage III given a placebo showed no such results. Twelve (12) of the 50 patients with stage III AIDS were withdrawn from the study because of loss of follow-up because of poor compliance: 7 from the placebo group and 5 from the treatment group. Eight (8) of the 50 patients with stage II AIDS withdrew, 2 from the placebo group and 6 from the treatment group.

There were no significant differences in patients with stage II disease.

A total of 25 different homeopathic medicines were prescribed based on the totality of patients' symptoms. The homeopathic potencies that were used included: 6X, 30C, 200C, LM3, LM5. The frequency of repetition of the " $X$ " and " $C$ " potencies ranged between once per day to three times per day. LM potencies were prescribed in water three or four times a day. The control group received a placebo that looked precisely like the active medicines and followed an identical protocol.

These researchers have published earlier less rigorous research that showed significant improvement in immune panels and blood work in HIV-positive patients and patients with AIDS after homeopathic treatment. One study evaluated the immunologic status of 34 HIVpositive patients (Singh et al., 1994). After 6 months of individualized homeopathic treat- ment, 23 (67\%) of the 34 subjects immune profiles improved. Thirteen (13) patients experienced a $0 \%-10 \%$ increase in CD4 lymphocytes (a higher number of CD4 lymphocytes suggests a stronger immune response) and 10 patients experienced a greater than $10 \%$ increase. Because there is a tendency for people with HIV to have continually decreasing CD4 lymphocytes, this suggests that homeopathic medicines may have provided a benefit to the subjects.

\section{CONTROLLED CLINICAL TRIALS TESTING HOMEOPATHIC GROWTH FACTORS}

Homeopathic medicines usually derive from the plant, mineral, or animal kingdom, but there is also a long history of using nosodes (medicines taken from pathologic organs or tissues, causative agents such as bacteria, fungi, ova, parasites, virus particles, and yeast, or excretions or secretions), allersodes (various antigens), and sarcodes (wholesome organs, tissues, or metabolic factors obtained from healthy specimens).

Several new homeopathic sarcodes have been prepared from recombinant human growth factors, several of which have not only been potentized, but have undergone homeopathic drug provings, and have been tested through randomized, double-blinded, placebocontrolled clinical studies.

Growth factors are well-characterized, multifunctional small polypeptides that regulate and coordinate immune, nervous, and endocrine communication in order to effectively and efficiently coordinate optimal functioning and defenses within the body. Pharmacologic doses of growth factors were tested on people with AIDS in the early 1990s, but they caused many side-effects, including increased HIV replication, suppression of lymphocyte proliferation, lymph node swelling, inhibition of macrophage function, and even increased morbidity and mortality compared to placebo (Lee et al., 1996).

In the late 1990s, Barbara Brewitt, Ph.D., a former National Institute of Health (NIH) scientist who has also conducted research at the 
University of Washington and Bastyr University, began a series of experiments and clinical studies using homeopathic doses of a combination of four growth factors (Brewitt and Standish, 1996a). Because growth factors are so important to immune, nervous, and endocrine function and cell-to-cell communication, and because large doses lead to dysregulation of immune function, including immunosuppression of various sorts, Dr. Brewitt theorized that homeopathic doses of growth factors may provide therapeutic benefits to people with HIV infection. Additionally, Dr. Brewitt recognized that growth factors used the same signaling pathways and DNA regulatory mechanisms within the cell as did HIV, thus presenting a possibility of growth factor signaling intervention to HIV pathogenesis.

Two preliminary double-blinded, placebocontrolled clinical studies (one original and one set of replication studies) in eight different cities throughout the United States over 8-16 weeks with 77 people with AIDS who used only natural therapies and no antivirals or steroids were conducted (Brewitt et al., 2002). Two other follow-up studies were conducted spanning 2.5 years that evaluated the long-term effects of these homeopathic medicines on 27 subjects in an open-label format (Brewitt et al., 2000). One of these follow-up studies compared natural approaches with and without homeopathic growth factors to antivirals drug therapies. Seven (7) subjects received homeopathic growth factors plus natural therapies, 6 subjects were given natural therapies without homeopathic growth factors, and 14 subjects were given conventional antiviral therapies (Brewitt et al., 2002).

The homeopathic medicines used in all of these studies were newly developed from those growth factors well known to have profound regulatory effects during $G_{1}$ phase of the cell cycle. This phase is critical to decision making about the cell's destiny for division, specialization, or death. HIV abrogrates $\mathrm{G}_{1}$ during HIV infection, thus, the decisions critical to immune system function, immune cell diversity, and the regulation of DNA expression are hostage to viral control rather than host cell control. The homeopathic treatments used in the studies consisted of a combination of four homeopathic growth factors: insulin-like growth factor-1, platelet-derived growth factor $\mathrm{BB}$, transforming growth factor $\beta-1$, and granulocyte-macrophage colony stimulating factors. Each of these medicinal agents were prepared homeopathically to the 30C, 200C, and/or $1 \mathrm{M}$ potencies (equivalent to $100^{-30}, 100^{-200}$, and $100^{-1000} \mathrm{~mol} / \mathrm{L}$, respectively). Patients were given 10 drops three times per day from each of four bottles of either the homeopathic medicines or placebo.

These studies found physical, immunologic, neurologic, metabolic, and quality-of-life benefits from the homeopathic growth factors:

\section{Physical benefits}

People given homeopathic growth factors did not experience a loss of lean mass, compared to losses of 3.5 pounds of lean mass within the first month of placebo or natural medicines only without the homeopathic medicines (Brewitt et al., 2002). Subjects receiving placebo had no positive physical changes toward ideal body weight. In contrast, $20 \%$ of the subjects receiving the homeopathic growth factors with more than $5 \%$ weight loss at study entry achieved ideal body weight 8-16 weeks later. These results were observed in earlier findings (Brewitt and Standish, 1996b). Thus, lean mass, a useful prognostic tool for longterm survival, and ideal body weight were achieved using homeopathic growth factors. Conventional drug therapy is well known for its adverse side-effect, lipodystrophy, an abnormal distribution of fat on the trunk of the body, simultaneous with loss of lean mass in the legs and arms.

\section{Immune benefits}

People given the homeopathic growth factors experienced reproducible stability or increases in CD4 counts, while people receiving placebo who were given other natural therapies such as herbs, supplements, acupuncture, and other natural approaches experienced significant losses of CD4 counts approximately 85 cells per microliter $(p=0.03)$. Similar changes were observed with CD8 counts. It was also observed that naive lymphocytes (CD45) that are resistant to HIV infection increased by 19 cells per microliter in 1 month, whereas HAART 
takes more than 36 months to achieve an increase in CD45 cells of 50 cells per microliter. (Pakker et al., 1998).

HIV viral load continually declined $-0.3 \mathrm{log}$ over 8 weeks and $-0.7 \log$ over 52 weeks, $(p<$ $0.01)$ for treatment versus placebo. In contrast, people with AIDS receiving placebo or only natural medicines had increasing viral loads. There was statistical difference in viral load between people taking HAART and people taking homeopathic growth factors plus other natural therapies. It is further significant to report that people with AIDS given homeopathic growth factors experienced no hospitalizations or new opportunistic infections during the 2.5year follow-up versus $25 \%$ and $40 \%$ hospitalizations and opportunistic infections in persons with AIDS undergoing HAART or using only natural medicines without homeopathic medicines.

\section{Neurologic benefits}

Subjects using the homeopathic growth factors had normalized measures in electrical conductance at the extremities after 8-12 weeks of treatment compared to placebo (Brewitt, 2002; Brewitt and Standish, 1996b). The improvements in electrical conductance paralleled improvements in immune function and lymphocyte cell count, thus suggesting that oral homeopathic growth factor therapy may have improved physiologic, neurologic, and immunologic parameters simultaneously.

\section{Metabolic benefits}

Subjects were found to have healthier levels of liver enzymes when they were given homeopathic growth factors (Brewitt and Standish, 1996b). Persons with high liver enzymes from the placebo group experienced a normalization of liver enzyme levels once they were crossed over to the homeopathic growth factor medicines. These subjects also reported less intestinal distress in terms of pain, bloating, gas, and diarrhea.

\section{Quality-of-life benefits}

A statistically significant improvement was found in subjects using the combination of homeopathic growth factors compared to placebo using a standard instrument (Medical Outcomes Study) to measure quality of life, physical functioning, and ability to complete daily routines including exercise (Brewitt and Standish, 1996a).

These results and replication of findings were small and preliminary studies, thus, one cannot yet determine what specific benefits accrued from the homeopathic growth factors. Larger studies conducted by independent researchers are needed.

\section{RESEARCH USING HOMEOPATHIC MEDICINES TO REDUCE THE SIDE- EFFECTS OF CONVENTIONAL MEDICATIONS}

As yet, only one study has asked the question: Can homeopathic medicines be used to reduce the side effects of conventional medications? Trimethoprim-sulphamethoxazole (TMP-SMX) is a drug used to prevent the onset of Pneumocystis carinii pneumonia (PCP). However, up to $80 \%$ of HIV-infected patients experience hypersensitive reactions to this drug. Researchers conducted an open, uncontrolled, prospective study using homeopathic doses of TMP-SMX to see if the side-effects of this drug could be reduced (Bissuel et al., 1995). Twenty (20) HIV-infected patients with a history of reactions in the previous 12 months were given a $9 \mathrm{C}$ dose twice daily for 10 days and then a 15C dose twice daily for 10 days prior to taking conventional doses of TMPSMX. With a mean follow-up of 6 months, 13 patients tolerated the TMP-SMX rechallenge well without any adverse reactions, and none developed PCP or toxoplasmosis during follow-up. Six patients developed skin reactions within 24 hours, one of whom later developed PCP and one who developed cerebral toxoplasmosis. One other patient developed a skin reaction within 3 months. Because two thirds of the patients responded well to the use of this homeopathic approach to desensitization, the researchers suggested that these findings be confirmed by a double-blinded, placebo-controlled trial. 
There is a body of research in animals that suggests that homeopathic doses of various organic and inorganic toxins help to excrete crude doses of that same toxin through the stool, urine, and sweat of the animal (Jonas et al., 2001; Linde et al., 1994), although few studies have been replicated by independent groups of researchers.

The implications of this body of research to AIDS drugs as well as other conventional drugs in general may be significant, although using homeopathic medicines to reduce the side-effects of conventional drugs in humans has been inadequately tested. On the other hand, homeopaths assert that homeopathic medicines have much greater applications than simply reducing the side-effects of conventional drugs (Ullman, 1991).

\section{RESEARCH ON VIRAL INFECTIONS AND DISEASES OF THE IMMUNE SYSTEM}

The only disease to date for which there has been multiple large-scale, double-blinded clinical studies conducted by independent researchers using homeopathic medications is influenza, a common viral condition (Casanova and Gerard, 1992; Ferley et al., 1989; Papp et al., 1998). These studies treated 487,300 , and 372 patients, and each yielded statistically significant results.

One blinded trial on chicken embryo viruses showed that 8 of 10 homeopathic medicines tested inhibited the growth of the viruses by 50\%-100\% (Singh and Gupta, 1985). A similar study done by the same researchers did find, however, that none of the four homeopathic medicines tested for their effects on a mouse virus had any effect, in part suggesting that not just any homeopathic medicine can or will have antiviral effects.

A laboratory trial tested the ability of homeopathic doses of tularemia to prevent onset of this disease in experimental mice (Jonas, 1999). In a series of 15 trials $(n=142)$, the mice given the homeopathic doses of tularemia lived longer. The protection rates averaged $22 \%$ over controls $(p=0.0037)$. Although conventional doses of the tularemia vaccine generally leads to $100 \%$ protection, this trial verified that homeopathic doses of a pathogen have a significant effect compared to placebo in the prevention of that same disease.

Other researchers have tested a homeopathic formula product that was given to 1440 piglets to prevent diseases of the respiratory tract, and this homeopathic product was found to be significantly more effective than placebo and routine low-dose antibiotic metaphylaxis (Albrecht and Schutte, 1999).

These various preliminary studies are individually and collectively intriguing, but they require replication from independent investigators before definitive statements can be made about them.

It should also be noted that homeopathic medicines are not thought to have effects on viral mechanisms of infection and replication but may have immunomodulatory effects (immunomodulatory effects refer to an ability to augment the immune response when it needs to be stimulated and to depress an already overstimulated immune system). One laboratory study showed that the homeopathic medicine silicea had dramatic effects on stimulating macrophages by $55.5 \%-67.5 \%$ (Davenas et al., 1987). Another trial suggested that individualized homeopathic medicines for the treatment of people with rheumatoid arthritis (Gibson, 1980), an autoimmune disease, might be effective.

There is further evidence of the immunomodulatory potential of homeopathic medicines (Bastide, 1987; Daurat et al., 1988).

\section{SUMMARY}

The history of the use of homeopathy for treating infectious diseases, the research that suggests the possibility of immunomodulatory effects from homeopathic medicines, and the clinical research on HIV-positive patients and patients with AIDS suggest that the possible benefit from homeopathic medicines may deserve the attention of physicians, scientists, and public health officials. Because of the seriousness of the AIDS epidemic, further research testing various homeopathic medicines is indicated. 
Despite a large number of people with AIDS using one or more alternative treatments (Fairfield, 2001), there are little formal data on their use and success. We may be overlooking valuable treatments, especially when people with AIDS take structured treatment interruptions, during which time homeopathic medicine may play a useful role as an adjunctive and/or alternative therapy.

\section{ACKNOWLEDGMENTS}

Special thanks to Kim A. Jobst, M.A., D.M., M.R.C.P., M.F.Hom., and Catherine Creel for reviewing and critiquing this manuscript.

\section{REFERENCES}

Albrecht H, Schutte A. Homeopathy versus antibiotics in metaphylaxis of infectious diseases: A clinical study in pig fattening and its significance to consumers. Altern Ther 1999;5:64-68.

Anderson W, O'Connor B, MacGregor R, Schwartz JS. Patient use and assessment of conventional and alternative therapies for HIV infection and AIDS. AIDS 1993; 7:561-566.

Barton S, Davies S, Schroeder K, Arthur G, Gazzard BG. Complementary therapies used by people with HIV infection [letter]. AIDS 1994;8:561.

Bastide M, Daurat V, Doucet-Jabeuf M, Pelegrin A, Dorfman P. Immunomodulatory activity of very low doses of thymulin in mice. Int J Immunother 1987;3: 191-200.

Bernard C. Principles of Experimental Medicine. Paris: Presses Universitaires de France, 1947:160-161.

Bissuel F, Cotte JB, Crapanne P, Rougier P, Schlienger I, Trepo C. Trimethoprim-sulphamethoxazole rechallenge in 20 previously allergic HIV-infected patients after homeopathic desensitization. AIDS 1995;9:407-408.

Blower SM, Aschenbach AN, Gershengorn, HB, Kahn JO. Predicting the unpredictable: Transmission of drug resistant HIV. Nat Med 2001;7:1016-1020.

Bradford TL. The Logic of Figures: The Comparative Results of Homeopathic and Other Treatments. Philadelphia: Boericke and Tafel, 1900.

Brewitt B. Bioelectomagnetic medicine and HIV/AIDS treatment: Clinical data and hypotheses for mechanism of action. In: Standish LJ, Calabrese C, Galantino ML, eds. AIDS and Complementary and Alternative Medicine: Current Science and Practice. Philadelphia: Churchill Livingstone, 2002:207-231.

Brewitt B, Standish LJ. Positive outcomes in treating human immunodeficiency viral (HIV) disease with high dilution growth factors [conference abstract]. Altern Ther 1996a;2:90.
Brewitt B, Standish LJ. High dilution growth factors/cytokines: Positive immunologic, anabolic, hematologic and clinical effects in HIV/AIDS patients. XIth International AIDS Conference, Vancouver, British Columbia, Canada, July 1996b.

Brewitt B, Traub M, Hangee-Bauer C, Patrick L, Standish LJ. Homeopathic growth factors as treatment for HIV: Recovery of homeostasis and functional immune system. In: Standish LJ, Calabrese C, Galantino ML, eds. AIDS and Complementary and Alternative Medicine: Current Science and Practice, Philadelphia: Churchill Livingstone, 2002:126-146.

Brewitt B, Traub M, Hangee-Bauer C, Patrick L, Standish LJ. Homeopathic growth factors: A low cost survival strategy for functional immunity and improved metabolism. XIIIth International AIDS Conference. Monduzzi Editore, Italy, July 2000, pp. 81-87.

Carwein VL, Sabo CE. The use of alternative therapies for HIV infection: Implications for patient care. AIDS Patient Care STDs 1997;11:79-85.

Casanova P, Gerard R. Review of 3 Annual Randomized Multicenter Studies of Oscillococcinum/Placebo. Oscillococcinum Rassegna Della Letterature Internationale. Milan: Laboratiores Boiron, 1992.

Coulter HL. Divided Legacy: A History of the Schism in Medical Thought, vol. II. Berkeley: North Atlantic, 1975.

Daurat V, Dorfman P, Bastide M. Immunomodulatory actvity of low doses of interferon in mice. Biomed Pharmacother 1988;42:197-206.

Davenas E, Poitevin B, Benveniste J. Effect on mouse peritoneal macrophages of orally administered very high dilutions of Silica. Eur J Pharmacol 1987;135:313-319.

de Visser R, Ezzy D, Bartos M. Alternative or complementary? Nonallopathic therapies for HIV/AIDS. Altern Ther 2000;6:44-52.

Dubos R. Struggle and partnership in the living world. In: The Mirage of Health. San Francisco: Harper and Row. 1959:93-94.

Fairfield KM, Eisenberg DM, Davis RB, Libman H, Phillips RS. Patterns of use, expenditures, and perceived efficacy of complementary and alternative therapies in HIV-infected patients. Arch Intern Med 1998;158:2257-2264.

Ferley JP, Zmirou D, D'Adhemar D, Balducci F. A controlled evaluation of a homeopathic preparation in the treatment of influenza-like syndrome. Br J Clin Pharmacol 1989;27:329-335.

Garrett L. HIV drugs losing power for many. San Francisco Chronicle. December 18, 2001; Nation \& World section: A3.

Gaucher C, Jeulin D, Peycru P, Pla A, Amengual C. Cholera and homeopathic medicine: The Peruvian experience. Br Homeopathic J 1993;82:155-163.

Gibson RG, Gibson SL, MacNeill AD, Buchanan WW. Homoeopathic therapy in rheumatoid arthritis: Evaluation by double-blind clinical therapeutic trial. Br J Clin Pharmacol 1980;9:453-459.

Jonas W. Do homeopathic nosodes protect against infection? An experimental test. Altern Thera 1999;5:36-40. Jonas W, Lin Y, Tortella F. Neuroprotection from gluta- 
mate toxicity with ultra-low dose glutamate. Neuroreport 2001;12:335-339.

Leary B. Cholera and homoeopathy in the nineteenth century. Br Homeopathic J 1987;76:190-194.

Lee PD, Pivarnik JM, Bukar JG, et al. A randomized placebo controlled trial of combined insulin-like GF-1 and low dose growth hormone therapy for wasting associated with human immunodeficiency virus infection. J Clin Endocrinol Metab 1996;81:2968-2975.

Linde K, Jonas WB, Melchart D, et al. Critical review and meta-analysis of serial agitated dilutions in experimental toxicology, Hum Exp Toxicol 1994;13:481-492.

Pakker NG, Notermans DW, deBoer R, Roos MT, de Wolf F, Hill A, Leonard JM, Danner SA, Miedema F, Schellehens PT. Biphasic kinetics of peripheral blood T cells after triple combination therapy in HIV-1 infection: A composite of redistribution and proliferation. Nat Med 1998;4;208-214.

Papp R, Schuback G, Beck E, Burkard G, Bengel J, Lehrl $S$, Belon P. Oscilloccinum in patients with influenzalike syndromes: A placebo-controlled double-blind evaluation. Br Homeopathic J 1998;87:69-76.

Rastogi DP, Singh V, Dey SK et al. Research studies in HIV infection with homoeopathic treatment. CCRH Q Bull 1993;15:1-6.

Richman D, Bozzette S, Morton S, Chien S, Wrin T, Dawson $\mathrm{K}$, Hellmann N. The prevalence of antiretroviral drug resistance in the US. Proceedings of the Interscience Conference on Antibacterial Agents and Chemotherapy, American Society for Microbiology, December 16-29, 2001, Chicago, IL.

Singh LM, Gupta G. Antiviral efficacy of homoeopathic drugs against animal viruses. $\mathrm{Br}$ Homoeopathic J 1985;74:168-174.

Singh N, Squier C, Sivek C, et al. Determinants of nontraditional therapy use in patients with HIV infection. Arch Intern Med 1996;156:197-201.
Singh V, Rastogi DP, Dey SK, Rao PK. Homoeopathic drugs as immunomodulators: A study of 34 HIV subjects [abstract PB0301]. International Conference on AIDS, August 7-12, 1994;10:218.

Sparber A, Wootton J, Bauer L, Curt G, Eisenberg D, Levin $\mathrm{T}$, Steinberg SM. Use of complementary medicine by adult patients participating in HIV / AIDS clinical trials. J Altern Complement Med 2000;6:415-422.

Standish L. Introduction to homeopathy. In: Standish LJ, Calabrese C, Galantino ML, eds. AIDS and Complementary and Alternative Medicine: Current Science and Practice, Philadelphia: Churchill Livingstone, 2002:115-125.

Ullman D. Discovering Homeopathy: Medicine for the 21st Century. Berkeley: North Atlantic, 1991.

Ullman D. Consumer's Guide to Homeopathy. New York: Jeremy Tarcher/Putnam, 1995.

Voelker R. HIV drug resistance, JAMA 2000;284:169.

Wolffers I, de Moree S. [Use of alternative treatments by $\mathrm{HIV}+$ and AIDS patients in The Netherlands]. Ned Tijdschr Geneeskd 1994;138:307-310.

Wootton J, Sparber A. Surveys of complementary and alternative medicine: Part III. Use of alternative and complementary therapies for HIV / AIDS. J Altern Complement Med 2001;7:371-377.

Address reprint requests to: Dana Ullman, M.P.H. Homeopathic Educational Services 2124 Kittredge St. Berkeley, CA. 94704

E-mail: mail@homeopathic.com 
